\title{
A comparison of sutureless and antibacterial suture abdomen closure
}

\author{
Okus $\mathrm{A}^{1}$, Karahan $\mathrm{O}^{1}$, Ay $\mathrm{S}^{1}$, Eryilmaz $\mathrm{MA}^{1}$, Unlu $\mathrm{Y}^{2}$, Aksoy N${ }^{1}$, Sevinc B ${ }^{1}$ \\ Konya Training and Research Hospital, General Surgery Clinic, Meram, Konya, Turkey. serdenay@yahoo.com
}

\begin{abstract}
Purpose: This experimental study aimed at comparing the cyanoacrylate abdomen closure to the effectiveness of triclosan coated polidioxanone abdomen closure.

Methods: The abdomen layers were closed with 3/0 polidioxanone suture in the first group. In the second group, the layers were closed with triclosan coated polidioxanone suture in a single layer. The abdomen layers of rats in the third group were attached with cyanoacrylates without sutures. The rats were sacrificed on the 14th day and the adhesive level was recorded. The incision resistance strength was measured. The tissue was examined blindly in the terms of inflammatory cell infiltration, capillary proliferation, fibrosis and micro-abscess by the pathologist. Results: No significant difference was determined between the 1st and 2nd groups in the terms of inflammatory cell infiltration, capillary proliferation, collagen deposition, fibroblast activity, adhesive and tissue distension strength. The fibrosis and adhesive rate of the 3rd group was significantly higher than the 1st and 2nd groups statistically. The tissue distension strength was lower than in the other groups and the differences between the groups were found to be significant $(p<0.05)$. No significant difference was determined between the groups in the term of micro-abscess.

Conclusions: Antibacterial suture is not superior to the conventional suture. It is concluded that cyanoacrylate is not an appropriate molecule for abdomen closure (Tab. 1, Fig. 3, Ref. 17). Full Text in PDF www.elis.sk. Key words: cyanoacrylate, tissue adhesive, octyl 2-cyanoacrylate, antibacterial suture, polidioxanone with triclosan, experimental study.
\end{abstract}

Post-laparatomy wound infection, bad wound healing might end in opening of the abdomen at the early period and incisional hernia at the late period. Complications such as infection, oedema, wound dehiscence at the incision line extend the length of hospital stay and increas the total hospital cost. These complications at the incision line are related to systemic factors like anemia, hypoproteinemia, azotemia, malnutrition, malignancy. As well as the type of the incision, closure method and suture material may contribute to complications.

The antibacterial effects of antibacterial sutures have been indicated in many studies. However, the results of them in the clinic studies are controversial $(1,2)$. Experimental studies have proved that cyanoacrylate which is used for skin closure can be used for intestinal anastomosis as well. However, no study has been published on the use of cyanoacrylate for abdomen closure.

This experimental study aimed at comparing the cyanoacrylate abdomen closure to the effectiveness of triclosan coated polidioxanone abdomen closure.

${ }^{1}$ Konya Training and Research Hospital, General Surgery Clinic, and ${ }^{2}$ Konya Training and Research Hospital, Department of Pathology

Address for correspondence: S. Ay, MD, Konya Training and Research Hospital General Surgery Clinic, Konya Egitim ve Arastirma Hastanesi Necip Fazil Mah. Atesbazi Sok. Meram Yeniyol PK: 42040 Meram, Konya, Turkey. Phone: +903323236709

Acknowledgement: This study was presented as an oral presentation at “6. Cerrahi Araştırma Kongresi” 08-10 December, 2011, Ankara, Turkey.

\section{Method}

This study was conducted at the Selcuk University Medicine Research and Application Centre with the 2010-52 numbered judgement and the research ethics committee approval.

46 months old 30 Wistar-albino rats of 200-300 gram weight were divided into 3 groups of 10 . No food limitation was applied to rats. The surgery was performed in general anaesthesia with intraperitoneal ketamine hydrochloride $(80 \mathrm{mg} / \mathrm{kg})$ and xylazin $(10 \mathrm{mg} / \mathrm{kg})$. After the hair was shaved, the area was cleaned with povidone iodine. Laparatomy was applied to all rats with 3 centimetre midline incision (Fig. 1).

The abdomen layers were closed with polydiaxonne suture (brand name Ethicon) in the 1st group, and with triclosan coated polydiaxonne suture (coated polydiaxonna Plus, Ethicon) at one take with continuous suture technique in the 2nd group. All layers were attached with cyanoacrylate (Ifabond-TM- Ifa medical, Greece) tissue adhesive in the 3 rd group.

The rats were sacrificed via decapitation. The abdomen was opened $1.5 \mathrm{~cm}$ from the incision with a reverse $U$ cut and the adhesives were photographed and recorded. The scale defined by Nair was used to evaluate the adhesive (3). 0: No adhesive, 1: Only one adhesive between the organs and the abdominal Wall 2: Two adhesives between the organs and the abdominal wall 3: Adhesive more than 2 between the organs and the abdominal wall and adhesive between the organs 4: One of the organs being adhesive to the abdominal wall (Fig. 2). Following this 


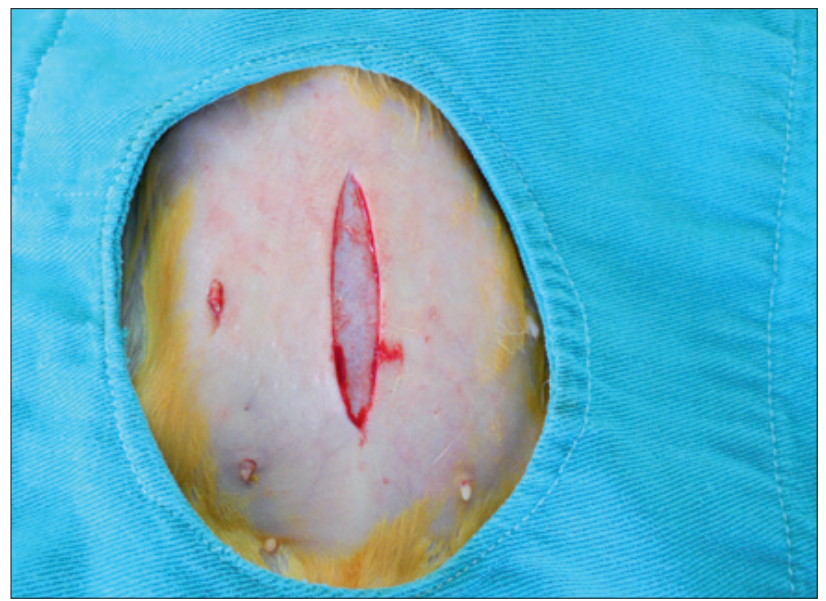

Fig. 1. Three centimetre incision.

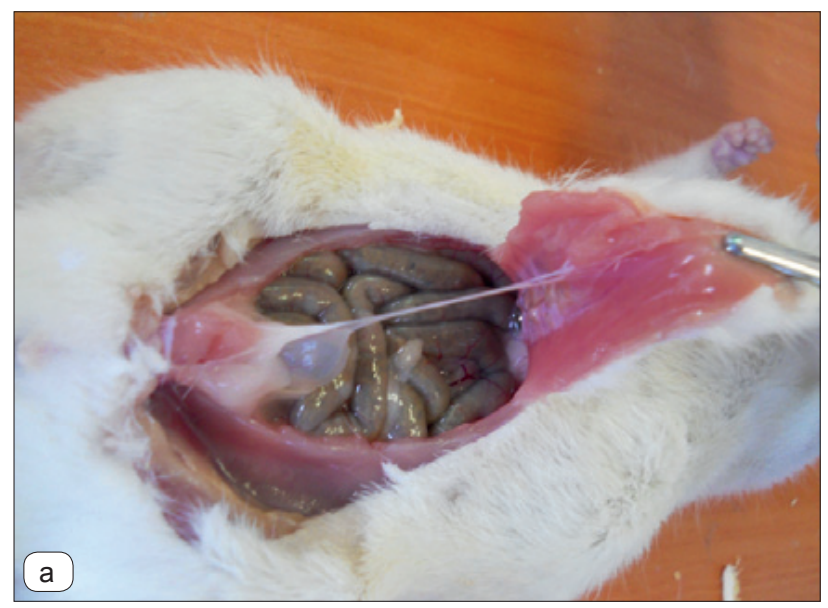

Fig. 2. a) 1st degree adhesive, b) 4th degree adhesive.

procedure, all incision lines were cut 1,5 $\mathrm{cm}$ from the incision and removed.

The incision line was fixed horizontally. The resistance strength of the incision line was measured with a digital electronic meter. The weight was raised gradually and the moment when the incision started to detach was recorded (Fig. 3).

The removed tissue (incision line) was evaluated blindly by a pathologist. Inflammatory cell infiltration was evaluated in the terms of capillary proliferation and fibrosis (collagen deposition amount) in the histopathological examination. The evaluation scale from 0 to 3 defined by Hooker et al was used in the evaluation (4). 0 : absent 1: mild 2: moderate 3: severe. Although the tissue was evaluated histopathologically for the micro-abscess in the incision line; 0: absent, 1: focal, 2: diffuse.

Two sample Kolmogorov-Smirnov test was applied for the evaluation of adhesive, Anova-Duncan test was applied for the incision resistance strength and Kruskall-Wallis test was applied for the other parameters. The tests were done with he tSPSS 15.0 packaged software and the $\mathrm{P}$ value under 0.05 was evaluated as significant.

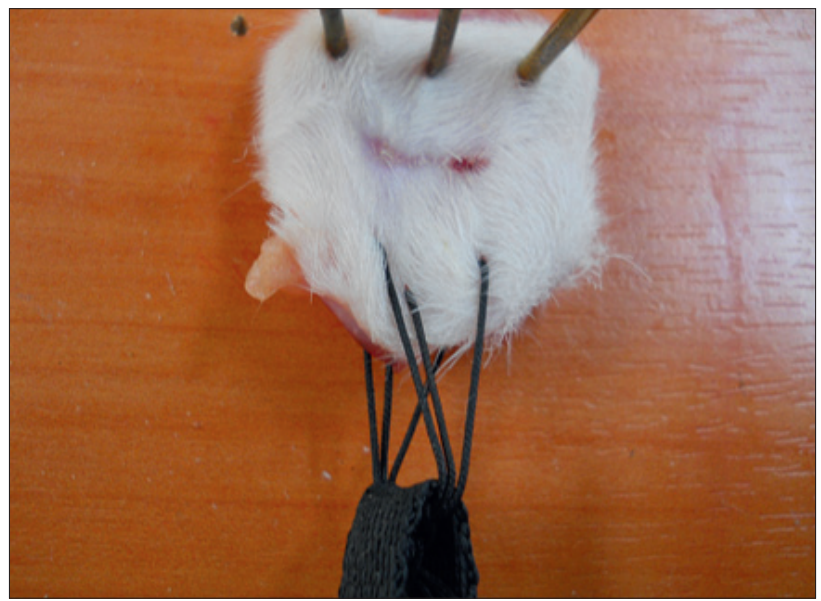

Fig. 3. Measurement of incision resistance strength.

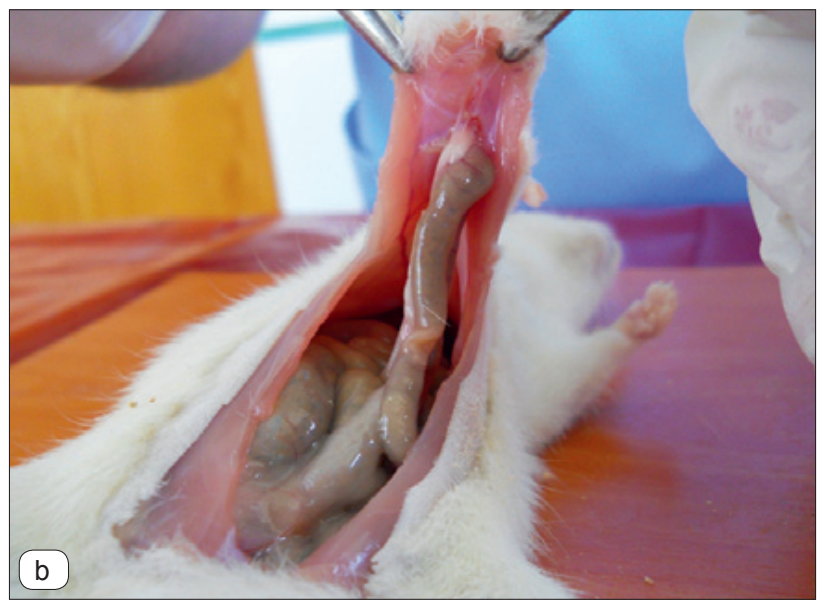

\section{Results}

No significant difference was determined between the 1st and 2nd groups in the terms of inflammatory cell infiltration, capillary proliferation, collagen deposition and fibroblast activity, which are indicatives of wound healing process. Similarly, there was no significant difference between these groups in the terms of adhesive and tissue distension strength. The adhesive rate of the 3rd group was higher and the tissue distension strength was lower than in the other groups and the differences between the groups were found to be significant $(\mathrm{p}<0.05)$. The fibrosis rate in the 3 rd group was significantly higher than in the 1 st and 2 nd groups statistically. No

\section{Tab. 1. Comparison of the groups.}

\begin{tabular}{lcccccc}
\hline & AR & IRS (gr) & ICI & CP & Fibrosis & micro-abscess \\
\hline GROUP 1 & 0,6 & 2580 & 2,2 & 1,3 & 1,3 & 0,5 \\
GROUP 2 & 0,5 & 2512,5 & 2,37 & 1,85 & 1,87 & 1,13 \\
GROUP 3 & $2,44^{*}$ & $1946,8^{*}$ & 2,71 & 1,85 & $2,28^{*}$ & 1,14 \\
\hline
\end{tabular}

Adehesive Rate - AR, Incision resistance strength - IRS, Tissue distention strength, Capillar proliferation - CP, Inflammatory cellule infiltration - ICI, * $\mathrm{p}<0,05$ 
significant difference was determined between the groups in the term of micro-abscess in the incision line (Tab. 1).

\section{Discussion}

Bad wound healing and infection of the incision line cause increase in morbidity and mortality. Antibiotic treatment for wound healing extends the length of the hospital stay and increases the total hospital costs. It causes delays in returning to work. There are many known risk factors for wound infection. One of the local risk factors is the used suture materials. It is known that bacteria are highly adherent against suture materials (5).

Antibacterial sutures that have been developed for more than 20 years create a chance for decreasing the surgical infections. In a in vitro experimental study, the antibacterial effects of the triclosan coated sutures, which prevent bacteria colonization (S. aureus, S. epidermidis) were determined (1). Storch et al proved in their experimental research in the animal model that triclosan coated ployglactin 910 prevented bacteria colonisation (Staphylococcus aureus) (6). Other similar experimental researches also indicated the antibacterial effects of triclosan coated sutures $(5,7$, 8). Besides, Bischofberger et al compared triclosan coated poliglactin 910 and poliglactin 910 in their double blind randomize animal study that they performed in 100 horses. In this study, it was determined whether antibacterial sutures were effective in incisional complications (9).

There is no consensus in the studies for the effectives of the antibacterial sutures. Justinger et al compared triclosan coated ployglactin 910 (vicryl plus) and ploydioxanon (PDS II) sutures in their retrospective study in 2088 patients and found out that the wound infection is significantly lower in the antibacterial suture group (10). Chen et al compared triclosan coated polyglactin 910 and ployglactin 910 in the cancer caused head-neck surgery in their prospective clinic study conducted on 253 patients and found no difference between the two groups in terms of surgical complications and wound site infection (11). Mingmalairak et al also compared triclosan coated polyglactin 910 and ployglactin 910 in their double blind randomized clinic study. They couldn't determine any significant difference between the two groups in terms of wound site infection in 100 appendectomy cases (12). Deliaert et al compared triclosan coated polyglactin 910 and ployglactin 910 in their double blind randomized clinic study on 26 breast reduction surgeries. Wound dehiscence of the group of antibacterial sutures was higher than the control group at a significant rate (2).

The data provided in literature above interestingly shows that there is no consensus on the clinic use of antibacterial sutures. Our experimental study has revealed that triclosan coated polydiaxon suture is not superior to the conventional polydiaxon suture. It is also suggested that the clinic use of triclosan coated antibacterial sutures has to be reconsidered by the high cost of triclosan.

Syanoacrilate is an industrial adhesive molecule and it is widely used in medicine. It has hemostatic and antibacterial properties besides being a strong adhesive (13). 2-octylcyanoacrylate has been used in skin closure since 1995 (14) and the studies have revealed that it is similar to the skin stapler in terms of cosmetic look and wound site infection (15).

Kanellos et al compared polypropylen and cyanoacriclate on colon anastomosis patients in their experimental study. No significant difference was found in terms of anastomosis bursting pressure. However, the adhesive rate of the cyanoacriclate group was higher than in the other group (16). In a study performed by Ersoy et al, gastric perforation model was created on the rats. They found out that cyanoacriclate addition to the closure with clip causes a significant increase on the bursting pressure. Similarly, the adhesive rate of the cyanoacriclate added group was found to be significantly higher (17).

Literature provides some studies on the anastomosis studies without suture with cyanoacriclate. However, this is the first study about its use in abdomen closure. Our study has revealed that cyanoacriclate use increases the adhesive like in the other studies. Moreover, the incision resistance strength of the abdomen closure with cyanoacriclate is lower than in the other groups of abdomen closure with sutures. As the adhesive rate and resistance strength is lower, it is concluded that abdomen closure with cyanoacriclate is not appropriate.

Consequently;

1. Antibacterial sutures are not superior to the conventional sutures.

2. Cyanoacriclate is not an appropriate molecule for abdomen closure.

Conflict of interest statement: there is no conflict of interest between the authors. There is no sponsor of the study. This study was conducted at Selcuk University Medicine Research and Application Centre with the 2010-52 numbered judgement and with the research ethics committee approval.

\section{References}

1. Rothenburger S, Spangler D, Bhende S, Burkley D. In vitro antimicrobial evaluation of Coated VICRYL Plus Antibacterial Suture (coated polyglactin 910 with triclosan) using zone of inhibition assays. Surg Infect 2002; 3 (Suppl 1): S79-87.

2. Deliaert AE, Van den Kerckhove E, Tuinder S, Fieuws S, Sawor JH, Meesters-Caberg MA, van der Hulst RR. The effect of triclosan-coated sutures in wound healing. A double blind randomised prospective pilot study. J Plast Reconstr Aesthet Surg 2009; 62 (6): 771-773.

3. Nair SK, Bhat KI, Aurora LA. Role of proteolytic enzyme in the prevention of postoperative intraperitoneal adhesions. Arch Surg 1974;108:849-53.

4. Hooker GD, Taylor BM, Driman DK. Prevention of adhesion formation with use of sodium hyaluronate-based bioresorbable membrane in a rat model of ventral hernia repair with polypropylene mesh--a randomized, controlled study. Surgery 1999; 125 (2): 211-216.

5. Edmiston CE, Seabrook GR, Goheen MP, Krepel CJ, Johnson CP, Lewis BD, Brown KR, Towne JB. Bacterial adherence to surgical sutures: can antibacterial-coated sutures reduce the risk of microbial contamination? J Am Coll Surg 2006; 203 (4): 481-489. 
$115-118$

6. Storch ML, Rothenburger SJ, Jacinto G. Experimental Efficacy Study of Coated VICRYL plus Antibacterial Suture in Guinea Pigs Challenged with Staphylococcus aureus. Surg Infect 2004; 5 (3): 281-288.

7. Gómez-Alonso A, García-Criado FJ, Parreño-Manchado FC, García-Sánchez JE, García-Sánchez E, Parreño-Manchado A, ZambranoCuadrado Y. Study of the efficacy of Coated VICRYL Plus Antibacterial suture (coated Polyglactin 910 suture with Triclosan) in two animal models of general surgery. J Infect 2007; 54 (1): 82-88.

8. Suárez Grau JM, De Toro Crespo M, Docobo Durántez F, Rubio Chaves C, Martín Cartes JA, Docobo Pérez F. Prevention of surgical infection using reabsorbable antibacterial suture (Vicryl Plus) versus reabsorbable conventional suture in hernioplasty. An experimental study in animals. Cir Esp 2007; 81 (6): 324-329.

9. Bischofberger AS, Brauer T, Gugelchuk G, Klohnen A. Difference in incisional complications following exploratory celiotomies using antibacterial-coated suture material for subcutaneous closure: Prospective randomised study in 100 horses. Equine Vet J 2010;42(4):304-9.

10. Justinger C, Moussavian MR, Schlueter C, Kopp B, Kollmar O, Schilling MK. Antibacterial [corrected] coating of abdominal closure sutures and wound infection. Surgery 2009; 145 (3): 330-334.

11. Chen SY, Chen TM, Dai NT, Fu JP, Chang SC, Deng SC, Chen SG. Do antibacterial-coated sutures reduce wound infection in head and neck cancer reconstruction? Eur J Surg Oncol 2011; 37 (4): 300-304.
12. Mingmalairak $C$, Ungbhakorn $P$, Paocharoen V. Efficacy of antimicrobial coating suture coated polyglactin 910 with tricosan (Vicryl plus) compared with polyglactin 910 (Vicryl) in reduced surgical site infection of appendicitis, double blind randomized control trial, preliminary safety report. J Med Assoc Thai 2009; 92 (6): 770-775.

13. Quinn J, Maw J, Ramotar K, Wenckebach G, Wells G. Octylcyanoacrylate tissue adhesive versus suture wound repair in a contaminated wound model. Surgery 1997; 122 (1): 69-72.

14. Díaz Barreiro P G, Servín Ramirez JF, Díaz Lopez DE. Experience with 10 cases of cutaneous suture with ethyl-cyanoacrylate adhesive. Initial report. Ginecol Obstet Mex 1995; 63: 10-14.

15. Ong J, Ho KS, Chew MH, Eu KW. Prospective randomised study to evaluate the use of DERMABOND ProPen (2-octylcyanoacrylate) in the closure of abdominal wounds versus closure with skin staples in patients undergoing elective colectomy. Int J Colorectal Dis 2010; 25 (7): 899-905.

16. Kanellos I, Mantzoros I, Demetriades H, Kalfadis S, Sakkas L, Kelpis T, Betsis D. Sutureless colonic anastomosis in the rat: a randomized controlled study. Tech Coloproctol 2002; 6 (3): 143-146.

17. Ersoy OF, Ozkan N, Celik A, Kayaoglu HA, Cakir E. Effect of cyanoacrylate on closure of gastric perforation: a comparative study in a rat model. Minim Invasive Ther Allied Technol 2009; 18 (4): 225-231.

Received May 30, 2012. Accepted December 16, 2012. 